\title{
Archaeological perspectives on the effects of medieval drought in prehistoric California
}

\author{
Terry L. Jones ${ }^{\mathrm{a}, *}$, Al Schwitalla ${ }^{\mathrm{b}, 1}$ \\ ${ }^{a}$ Department of Social Sciences, California Polytechnic State University, San Luis Obispo, CA 93407-0329, USA \\ ${ }^{\mathrm{b}}$ Department of Anthropology, California State University, Sacramento, $6000 \mathrm{~J}$ Street, Sacramento, CA 95819, USA
}

\begin{abstract}
Inspired by Stine's [1994. Extreme and persistent drought in California and Patagonia during Mediaeval Time. Nature 369, 546-549.] findings from Mono Lake and Graumlich's [1993. A 1000-year record of temperature and precipitation in the Sierra Nevada. Quaternary Research 39, 249-255.] tree-ring study from the southern Sierra Nevada, California archaeologists have for over a decade been investigating the possibility that prehistoric societies were noticeably impacted by severe droughts during the Medieval Climatic Anomaly (MCA; cal A.D. 800-1350). Decreased production at obsidian sources, dramatic increases in bead production, trade, and sociopolitical complexity in the Channel Islands, and subsistence changes on the central coast were among the trends attributed to drought-related demographic stress by researchers in the 1990s. Review of more recent archaeological research shows that as the search for signs of unusual cultural changes during the MCA has broadened, some of these early patterns (e.g. violence and health problems) have been found to be more complicated and regionally varied than previously thought while others (e.g., settlement disruption, deterioration of long distance trade, and population movements) have been further corroborated.
\end{abstract}

\section{Introduction}

Over 10 years ago in a highly influential paper, Stine (1994) presented strong evidence for the occurrence of anomalously prolonged and severe droughts during Medieval times in California and Patagonia. The presence of roughly contemporaneous "drowned stumps" in these two different parts of the world led Stine to redefine what Lamb (1965) had earlier identified as the Medieval Warm Period. Using radiocarbon findings from the tree stumps, Stine dated the Medieval Climatic Anomaly (MCA) between A.D. 800 and 1350 and characterized it not as a period of uniformly warm climate, as had Lamb, but rather as an interval marked by unusually long and severe droughts. Tree-ring studies, particularly the findings of Graumlich (1993) from the southern Sierra Nevada (also LaMarche 1973, 1974) provided independent support for both the timing and severity of Medieval droughts in California. While the effects of the Medieval

\footnotetext{
${ }^{*}$ Corresponding author. Tel.: + 18057562523 ; fax: + 18057567019 .

E-mail addresses: tljones@calpoly.edu (T.L. Jones),

schwitalla@pacificlegacy.com (A. Schwitalla).

${ }^{1}$ Tel.: + 19163965358.
}

Warm Period had been considered before in the region (e.g., Moratto et al., 1978; Moratto, 1984), the refined characterization that emerged in the mid-1990s inspired California archaeologists to consider anew the possibility that severe climatic events late in the Holocene had significant impacts on prehistoric people. Gilreath (1995), for example, suggested that a drop-off in production at the Coso obsidian quarry in southeastern California ca. A.D. 1150, was the result of drought-related problems in inter-group relations. Jones (2003) suggested that a distinctive settlement disruption on the central California coast ca. A.D. 1250 was caused by movements of people in response to drought. Subsequently, drought-related problems were detected on the islands and mainland of southern California (Fischman, 1996; Raab and Larson, 1997), and a broad, systematic review produced signs of varied responses to drought across much of southwestern North America, including the Sierra Nevada, the Great Basin, the Mojave Desert, and the Colorado Plateau (Jones et al., 1999). This widespread evidence was subsequently acknowledged in extra-regional studies (e.g., Fagan, 2004) including several that compared the responses of prehistoric people to drought to those of modern societies (deMenocal, 2001; Cook et al., 2004). 
The Medieval droughts hypothesis has not, however, been accepted by all. Both Basgall (1999) and Bettinger (1999) argued that most late Holocene cultural changes in California were more likely caused by population growth and economic intensification rather than environmentally induced problems. Bettinger (1991) made this case originally for the White Mountains in eastern California, while Basgall (1987) argued for subsistence intensification in the North Coast Ranges. In light of these alternative views, a considerable amount of archaeological research has been completed in the last decade to address the issue of human response to Medieval droughts in California. In this paper we review this recent research, beginning with some of the theoretical and empirical assumptions advanced in the initial dialog on droughts and demographic stress in prehistoric western North America. This is followed by regional and topical reviews that continue to show compelling but not unequivocal evidence for the impacts of drought on human populations in many regions of California during the MCA. Some of the earlier predictions, however, have not been corroborated with new data while some previously unanticipated responses to drought have also been identified. The objective here is to summarize recent evidence for the possible impacts of Medieval droughts on human populations rather than to review the evidence for the droughts themselves, however alternative views on the chronology, duration, and severity of environmental events during the MCA have also emerged in the last decade. Stine (1994) originally dated the MCA to cal A.D. $800-1350$ and defined it as being marked by droughts of anomalous severity and duration relative to the millennium that preceded them. More precisely, based on radiocarbon-dated stumps, he identified prolonged droughts between ca. cal A.D. 900-1100 and A.D. 1200-1350, separated by a wet interval. Graumlich's tree-ring study produced more refined dating of the droughts in the Sierra Nevada, dating them from A.D. 1020-1070, 1200-1217, and 1250-1365. She also posited generally warm temperatures for the entire period between ca. A.D. 1100 and 1375. The combined record from the Sierra Nevada, Mono Lake, and the White Mountains shows drought and/or warm climate between cal A.D. 1250 and 1330 , preceded by a wet interval (cal A.D. 1100-1150) and an earlier drought (cal A.D. 1020-1050).

Stine explicitly defined the MCA as anomalous in terms of the severity of the prevalent conditions. Inherent in his characterization was the notion that the Medieval droughts would have presented Native populations with environmental problems outside the range of their most recent experience. A slightly different characterization was put forth by Kennett (2005), Kennett and Kennett (2000), and Kennett et al. (2007), who, based on sea surface temperature reconstructions from oxygen isotope analysis of microfossils from deep sea sediment cores, envision the MCA as only the end of a longer period (ca. cal A.D. 450-1350) of cool seas and general aridity that culminated in extreme droughts between cal A.D. 950 and 1150 and
A.D. 1250-1350 (Kennett, 2005, pp. 68-71). While this reconstruction is not wholly inconsistent with Stine's portrait, it de-emphasizes the anomalous character of events between cal A.D. 800 and 1350 period. It does corroborate a two-pronged interval of extreme aridity separated by a period of amelioration. All of the paleoclimatic reconstructions, however, show the periods of cal A.D. 1020-1070 and $1250-1330$ as times of severe drought.

\subsection{Portents of cultural change: anticipated effects of prolonged drought on native societies of Western North America}

Early considerations of the possible effects of prolonged droughts on prehistoric societies focused on the American Southwest where tree-ring studies (Douglass, 1929) provided precise chronologies for both droughts and archaeological complexes. Wormington (1947) was among the first to suggest that prehistoric agriculturalists would have been highly susceptible to prolonged decreases in rainfall owing to their heavy reliance on crops. Absent tree-ring dating, the possible effects of droughts on hunter-gatherer populations outside of the Southwest were not seriously considered until later, although the likelihood that the early-mid-Holocene aridity was associated with reduced human presence in the Great Basin (Antevs' (1948) Altithermal) has been debated intermittently for over half a century (see Basgall and Hall, 1992; Baumhoff and Heizer, 1965; Broughton and Bayham, 2003; Byers and Broughton, 2004; Cleland and Spaulding, 1992; Grayson, 1993, pp. 210-216; Jennings, 1964; Mikkelsen et al., 2000). Antevs (1948, 1955) defined the Altithermal as a 3000-year period of warm, dry climate which differs considerably from Stine's definition of the MCA. Nonetheless, Antevs' notions of the likely effects of elevated aridity on prehistoric populations (e.g., reduced rainfall, drying wetlands, depletion of resources, and reduction in human populations) have been carried forward in more recent ideas about the likely impacts of the Medieval droughts on California's Native societies.

Moratto et al. (1978) and Moratto (1984) were the first to focus on late Holocene aridity/droughts in California. Relying largely on LaMarche's $(1973,1974)$ tree-ring studies from the White Mountains, Moratto et al. (1978, p. 155) defined the period from 600 to 1400 years ago as a time of rapidly warming and drying climate, and set out clear expectations for the effects of these conditions on Native people: dispersal of human populations, deterioration of political organization, increased violence, disruptions in inter-regional exchange, increased mobility, and reduced occupation of some areas (e.g., the Truckee River, the southern Sierra foothills, and the Central Valley). These exclusively negative outcomes were attributed to a period longer than what Stine subsequently defined as the MCA. In a prelude to more recent discourse, Moratto et al.'s proposals were immediately challenged by Byrne (1979) who suggested, among other things, that Holocene 
climatic variability was not nearly as great as the authors suggested.

\subsection{Land versus sea and the problem of environmental determinism}

The 1990s debate over the effects of environmental variability on prehistoric California societies actually began several years prior to Stine's definition of the MCA. In a series of highly influential papers, Arnold (1991, 1992a, b, 1993, 1995) proposed that the Chumash on the northern Channel Islands of the southern coast were effected by elevated sea surface temperatures and an associated decline in marine productivity between A.D. 200 and 1200. The period of warm seas was based on a preliminary Holocene sea surface temperature chronology developed by Pisias (1978). Arnold (1992a, b) subsequently likened this period to a prolonged El Niño event and suggested that the Chumash were most severely impacted by reduced marine productivity ca. cal A.D. 1150 at which time there was a disruption in settlement, a dramatic increase in the production of shell beads on the islands, and increased cross-channel trade. The latter was thought to represent attempts by islanders to obtain more food from the mainland through exchange. With this proposal, Arnold broke from previous characterizations of human response to environmental problems of the Medieval era by identifying positive developments (e.g., increased bead production and emergent sociopolitical complexity) as opposed to strictly negative ones. While the paleoenvironmental premises underlying her model were ultimately found to be faulty (see Raab and Larson, 1997; Jones and Kennett, 1999; Kennett and Kennett, 2000; Kennett, 2005), Arnold identified a strong pattern in the Island archaeological record that runs counter to previous characterizations of exchange trends during the Medieval Period. While the earlier proposals were susceptible to the charge of environmental determinism (positing an inevitable crisislike response to drought), Arnold's model suggested that environmental flux could prompt changes of varied character. She further brought to the fore the complexities involved in modeling the responses of coastal huntergatherers to environmental variability. While the effects of drought on terrestrially adapted peoples would seem to be relatively straight-forward (e.g., decreased rainfall, fewer water sources, lowered biotic productivity, decreased game populations), coastal foragers would have had an array of marine resources to turn to in the face of the decreasing viability of terrestrial biomes. People on the Channel Islands, in particular, had exceptionally productive marine resources at their disposal. Further, in the cyclical climatic variation associated with the El Niño Southern Oscillation (ENSO), declines in marine productivity are associated with warm seas, greater rainfall, and increased productivity of terrestrial habitats. Recognizing crises among maritime hunter-gatherers is decidedly more complicated than for interior populations with more one-dimensional subsistence regimes. Jones et al. (1999) subsequently emphasized the likelihood that anomalously severe droughts could force cultural changes but not necessarily wreak havoc. In the review that follows, the evidence for cultural change unearthed in the last 10 years or so in response to the Medieval droughts hypothesis is evaluated - first regionally and then topically considering issues of health, violence, and technology.

\section{Regional responses to the MCA}

Owing to a long history of group migrations and populations replacements attested to by an intricate linguistic mosaic, California's archaeological record is complex and regionally varied. Some but not all of the group movements that fostered this linguistic diversity were probably related to environmental events including those of the MCA. The state's prehistory is also complicated by a highly diverse natural setting that includes temperate forests on the North Coast and highly xeric deserts in the southern interior. The effects of prolonged droughts on this varied natural landscape would have been equally complex and regionally variable as certain areas would have experienced significant declines in biotic productivity while others (e.g. the lower Sacramento Valley, North Coast Ranges) may have been less effected. Regions where research has been explicitly directed toward identifying archaeological responses to Medieval droughts include the islands and mainland of the Southern California Bight, the Sierra Nevada, the Central Coast, and the Mojave Desert. More limited research has been undertaken in the San Francisco Bay, the Central Valley, Northwestern and Northeastern California (Fig. 1).

\subsection{The Southern California Bight}

The southern coast continues to be a primary focus for debate on the effects of late Holocene climate in California. Findings are available from most of the individual Channel Islands (Kennett and Kennett, 2000; Yatsko, 2000; Arnold, 2001a,b; Raab et al., 2002; Munns and Arnold, 2002; Vellanoweth et al., 2002; Kennett, 2005; Rick, 2004, 2007; Kennett et al., 2007) and the adjacent mainland (Rosenthal et al., 2001; Erlandson and Rick, 2002; Gallegos, 2002; Gamble and Russell, 2002; Glassow, 2002; York, 2006). Among these are a number of studies that raise serious questions about reduced marine productivity during the Medieval Period. Erlandson (1993) findings from a component dating A.D. 1150-1550 on the Santa Barbara mainland at CA-SBA-1731 showed a significant density of fish remains which runs counter to the claims made by Arnold (1992a,b). Subsequently, Kennett and Kennett's (2000) improved, high-resolution sea temperature reconstruction for the Santa Barbara Channel showed that the A.D. 450-1350 period was marked by cold sea surface temperatures, high marine productivity, and general aridity (see also Kennett and Conlee, 2002). Kennett (2005) 


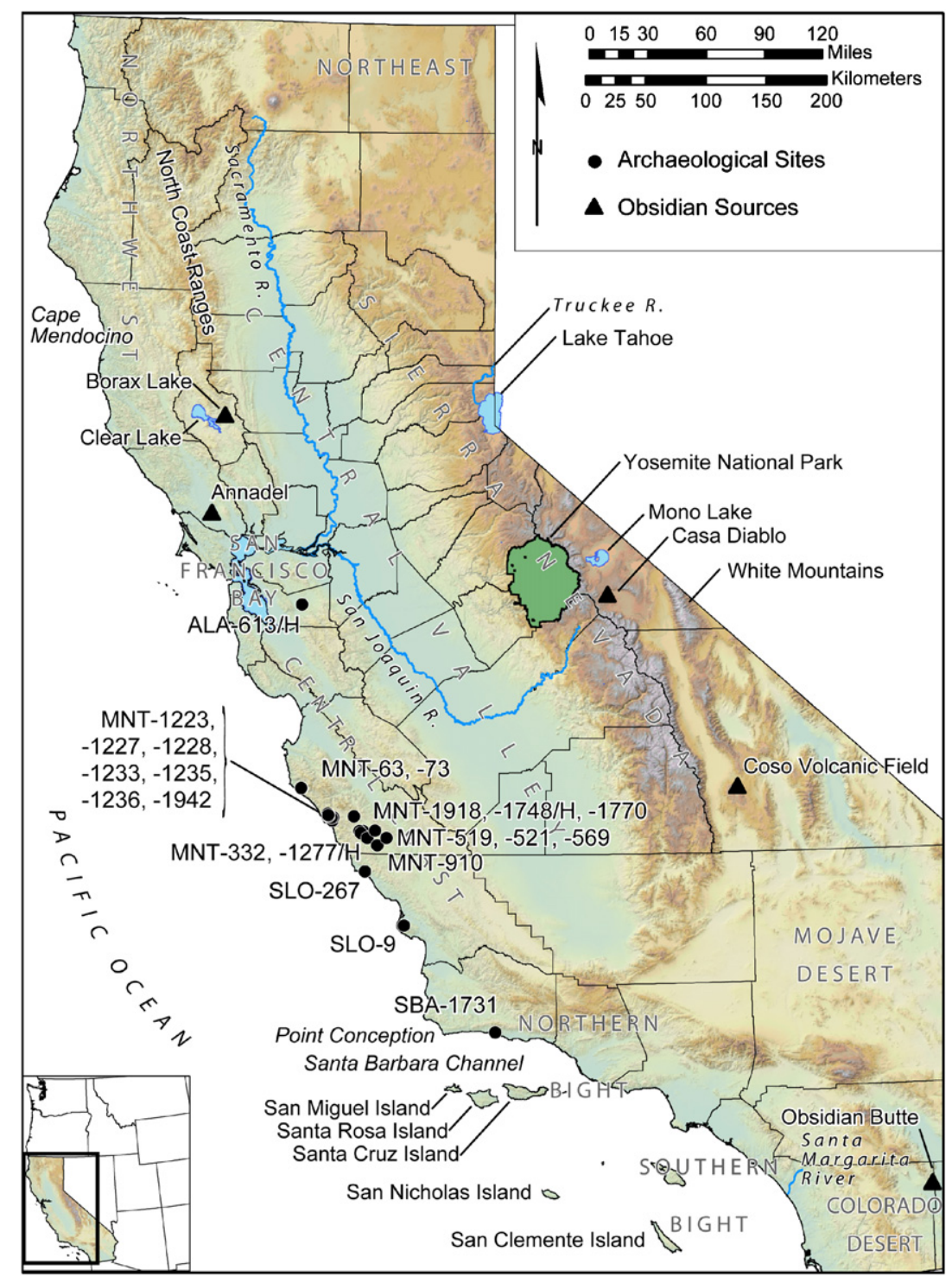

Fig. 1. Regions of California and locations mentioned in the text.

interpreted this pattern as consistent with sustained terrestrial drought, specifically between cal A.D. 1000 and 1350. He also emphasized that the cal A.D. 450-1350 period was marked by extreme variation, and further argued that climatic instability associated with persistent drought was the cause of resource stress and competitive aggression during the A.D. 1150-1300 period although lethal violence began to increase earlier ca. cal A.D. 500. Subsequent studies continue to document dense concentrations of fish bone in deposits dating to the Medieval Period (Colten, 1995, p. 98, 2001, p. 201; Rick, 2004), and there seems to be little remaining justification for associating the MCA with reduced marine productivity (cf. Arnold and Tissot, 1993; Colten, 2001).

At the same time that paleoenvironmental reconstructions improved, events transpiring across the Middle-Late Transition (cal A.D. 1150-1300) in the Santa Barbara Channel have also been more closely scrutinized. Items of material culture that have been the foci of these re-evaluations include shell beads (Arnold and Graesch, 2001; Kennett and Conlee, 2002, pp. 157-161), the artifacts associated with their production (e.g., microblade drills, microblade cores, and bead detritus) (Preziozi, 2001; Kennett and Conlee, 2002, pp. 158-161) and the sewnplank canoe (Arnold, 1995; Bernard, 2001; Arnold and Bernard, 2005). One of the most compelling aspects of Arnold's original model was the strong evidence for a punctuated increase in bead manufacture after ca. cal A.D. 1150 on Santa Cruz Island (see Arnold, 1992b, p. 138). Arnold (1995) further linked this increased production to the emergence of craft specialization (organized and directed by elites) and increased use of sewn-plank canoes (the Chumash tomolo). More recent research shows, however, that trends involving beads and boats in the Santa Barbara Channel ca. cal A.D. 1150-1300 were less punctuated and more gradual than originally thought. Both Colten (2001, p. 217) and Kennett and Conlee (2002) document gradually increases in bead manufacturing 
beginning ca. cal A.D. 400-700. Radiocarbon dates indicate that the sewn plank canoe also originated in the Santa Barbara Channel during this interval (Gamble and Russell, 2002), possibly due to external contact (Jones and Klar, 2005; Klar and Jones, 2005). The remains of pelagic fish, used as a proxy for tomolo use likewise show incremental increase beginning ca. cal A.D. 500, continuing into post-Medieval times (Arnold and Bernard, 2005; Bernard, 2001).

While more recent research has failed to corroborate certain aspects of Arnold's punctuated change model, Arnold (1992b, p. 134) was the first to recognize that the late Medieval Period was also marked by a distinctive disruption in settlement on the Channel Islands. Subsequent research has corroborated that few sites were continuously occupied through the Middle-Late Transition (cal A.D. 1150-1300) on Santa Cruz (Munns and Arnold, 2002, p. 135), San Miguel (Rick, 2004) or San Clemente Island (Yatsko, 2000, 2003). On the latter, Yatsko (2000, p. 121) showed that the population was significantly reduced during the MCA with settlements concentrated near predictable sources of water. Preliminary findings from San Nicholas Island likewise suggest partial abandonment during the cal A.D. 1150-1300 period (Vellanoweth et al., 2002, p. 90). Widespread evidence for disruption and partial abandonment of both the southern and northern Channel Islands remains the most compelling evidence for the impact of droughts in the Southern California Bight. Dietary patterns show evidence for a reliance on fish during this period (Colten, 2001; Rick, 2004), but there is nothing to suggest an anomalously intense focus on marine resources (Colten, 2001, p. 203; Rick, 2004). Rather, the greatest reliance on fish is evident afterwards during the Late Period (Colten, 2001, p. 203; Munns and Arnold, 2002, p. 139; Kennett, 2005).

The mainland coast of the Southern Bight also provides mixed support for environmentally induced culture change between ca. cal A.D. 800 and 1350. Radiocarbon date frequencies suggest a significant increase in population after cal A.D. 1300 (Glassow, 2002, p. 201). On the Santa Barbara Coast, Erlandson and Rick (2002, p. 182) note that very few sites were occupied during the Middle-Late Transition (cal. A.D. 1150-1300), supporting the idea that prolonged droughts resulted in an aggregation of settlements. Further to the south, in what are now Ventura and Los Angeles counties, Gamble and Russell (2002) report no evidence of environmentally induced settlement or subsistence change during the late Holocene. Gamble (2005) is one of the most outspoken opponents of the Medieval drought hypothesis and argues that late Holocene was marked by increasingly complex economic and political organization as resources from a wide variety of environments were used more efficiently as populations grew. Gamble (2005) has further argued that attempts to attribute late Holocene cultural changes to environmental catastrophe overlook indigenous knowledge of the California resource base, the abilities of Native people to develop new technologies to help cope with environmental problems, and the existence of cultural mechanisms that allowed for redistribution of resources within populations (e.g., social responses to crisis; see also Johnson, 2000). In regard to the Medieval droughts, she points to the existence of well-crafted storage baskets that she feels would have allowed Native people to deal effectively with droughtrelated decreases in water.

Even further south in the area of modern-day Orange and San Diego counties, the archaeological record shows strong evidence of cultural change predating the MCA, ca. cal A.D. 600-700 (Koerper et al., 2002). At the time of historic contact, this region was inhabited by people who were considerably less maritime than the Chumash and Gabrelino/Tongva, and who focused their subsistence efforts on terrestrial resources and inland habitats (Christenson, 1992; Jones, 1992). A longstanding consensus suggests that this terrestrial adaptation was preceded by an earlier one that involved greater reliance on estuarine and coastal resources (Warren, 1968; True, 1990; cf. Byrd, 1998; Byrd and Reddy, 2002). The shift from a marine to terrestrial adaptation is generally attributed to silting-in and deterioration of coastal estuaries late in the Holocene (Warren, 1968; Rosenthal et al., 2001). This adaptive shift preceded and was mostly unrelated to the MCA, but some affects of the MCA are nonetheless recognized. In Orange County, radiocarbon date frequencies show incremental increase after ca. cal A.D. 1 with a peak at cal A.D. 1300 and a steep decline thereafter which Koerper et al. (2002, p. 68) attribute to decreased human population during the MCA. In a thoughtful analysis of findings from the lower Santa Margarita River in northern San Diego County, York (2006) noted that molluscan remains from deposits dating to the MCA were dominated by salt-tolerant taxa (e.g., Chione sp.) that reflect periods of low flow in the river and frequent closure of its lagoon. These same middens also produced the remains of non-lagoonal species (Donax gouldii) which suggest that foragers exploited more distant, open-coast habitats in the face of the non-viability of the Santa Margarita estuary. York (2006, p. 51) notes an impressive synchrony between the dating of the Chionedominated deposits and the MCA. While the overall shift from a marine to terrestrially based adaptations in San Diego and Orange counties is generally consistent with gradual reduction in the productivity of coastal estuaries, droughts during the MCA seem to have accelerated this process in some drainages. Gallegos (2002), however, is correct in noting that there is considerable variation in the chronology of lagoon deterioration along the coast of San Diego County and generalizations about events in the Santa Margarita River drainage do not necessarily hold for all of the Southern Bight mainland.

As in other regions, the San Diego area also experienced a breakdown in long-distance trade at the onset of the Late Period when obsidian from the Coso source in southeastern California no longer arrived in the area and was replaced with glass from less-distant Obsidian Butte 
(Fig. 1). True (1990) suggested that many of the cultural changes that mark the onset of the Late Period in the region may reflect a reduction in rainfall and concentration of populations on a few reliable water sources. Gallegos (2002, p. 35) suggested that a shift to cremation as the preferred mode for disposition of the dead at this time could reflect increased health problems due to drought and the need to dispose of the dead in a more effective manor. Despite these proposals, the San Diego area remains somewhat problematic with respect to the droughts hypothesis owing to a coarse-grained culture history in which these changes are associated with a period between approximately 1500 and 1000 years ago.

\subsection{Sierra Nevada}

Following the pioneering ideas put forth by Moratto et al. (1978), the Sierra Nevada continues to be a major focus of research on the effects of drought in prehistoric California. Most recently Hull (2007) and Hull and Moratto (1999) argued that there was a significant shift in human use of the range during the late Holocene marked by substantial changes in technology, trade, subsistence, settlement, and population. Hull (2007) notes that between ca. cal A.D. 500 and 1250 there was a substantial population decline along the entire length of the western slope of the Sierra, including the northern Sierra, the lower elevation zones of the central and southern Sierra, and in mid-elevation zones of Yosemite National Park. Hull is somewhat hesitant to attribute these changes exclusively to Medieval droughts, noting that a host of both long- and short-term climatic trends and volcanic activity in the InyoMono region may have affected the changes evident in the archaeological record. Hull and Moratto (1999), however, were more inclined to associate these signs of cultural change with the MCA. It should be noted, however that changes transpiring at cal. A.D. 500 are too early to attribute to the MCA as it was originally defined by Stine although the date of cal A.D. 500 does figures prominently in Kennett's (2005) interpretations for the Santa Barbara Channel. Owing to an unfortunate but necessary reliance on obsidian hydration in the Sierra Nevada region, absolute chronologies also very approximate which leaves open the possibility that regional settlement changes may correlate with the later date of cal A.D. 800 MCA.

More fine-grained studies in the northern Sierra Nevada have corroborated the general pattern of depopulation during the MCA. At CA-AMA-56 in the central Sierra foothills, Wohlgemuth (2005) reported evidence for population decline during the MCA, while Waechter (2005) found an extensive series of features apparently related to collection and processing of camas bulbs and dating between cal A.D. 980 and 1460 which she interpreted as evidence for resource intensification during the MCA.

\subsection{The Central Coast}

The Central Coast region between Monterey Bay and Point Sal has also figured prominently in discussions of the affects of Medieval droughts in California. Three patterns were identified by Jones et al. (1999): settlement disruption comparable to that of the northern Channel Islands, deterioration in inter-regional exchange indicated by the disappearance of obsidian (a trade good available only from distant sources in northern and eastern California), and a marked change in tool assemblages. Further research has corroborated these patterns.

In a systematic evaluation of subsurface data from 284 sites, including over 1200 radiocarbon determinations, Jones et al. (2007) corroborated signs of settlement change across the MCA. The period between A.D. 1000 and 1500 shows that more sites were occupied than during any other time in the region's prehistory, with a $100 \%$ increase over the previous half millennium (Fig. 2). However, a marked increase in site abandonments is also apparent beginning at cal A.D. 1250 (Fig. 3). Together, these patterns seem consistent with large-scale movements of people, particularly movement to the coast from the interior. Survey findings by Whitley et al. (2004) from the Carrizo Plain in the southeastern interior of the Central Coast suggest widespread abandonment of that area immediately preceding population build-up on the coast.

The obsidian record also continues to suggest that longdistance exchange broke down by the end of the MiddleLate Transition. A review of obsidian findings from a large sample of sites in southern Monterey and northern San Luis Obispo counties (Jones, 2003) adds further support to the idea that obsidian is considerably more common in deposits predating cal A.D. 1000 than it is in those postdating cal A.D. 1000 (Table 1). Coincident with the decline in obsidian and long-distance trade is the appearance of evidence for greater and more widespread production of shell beads after cal A.D. 1250. Bead production on the Central Coast was neither as intensive nor as centralized as in the Santa Barbara Channel, but Late Period deposits consistently produce more shell and stone beads than middens from earlier periods, along with bead drills and bead manufacturing detritus. Since shell beads were a medium of exchange in Native California, this marked increase seems to suggest a significant increase in localized trade after the MCA.

Recent findings from a salvage excavation at site CA-SLO-9 in Montaña de Oro State Park in San Luis Obispo County further hint at the nature of human response to the MCA in this region (Codding and Jones 2006). Radiocarbon determinations from this site indicate that it was occupied between cal A.D. 900 and 1300 (Table 2). Bird and mammal bones (Table 3) show an emphasis on rabbits (Sylvilagus spp.; NISP $=37,27.1 \%$ ), cormorants (Phalacrocorax sp.; NISP $=30,21.9 \%$ ), and sea otters (Enhydra lutris; NISP $=18,13.1 \%$ ). Bones of deer were remarkably uncommon in the deposit, and 
Number of Sites

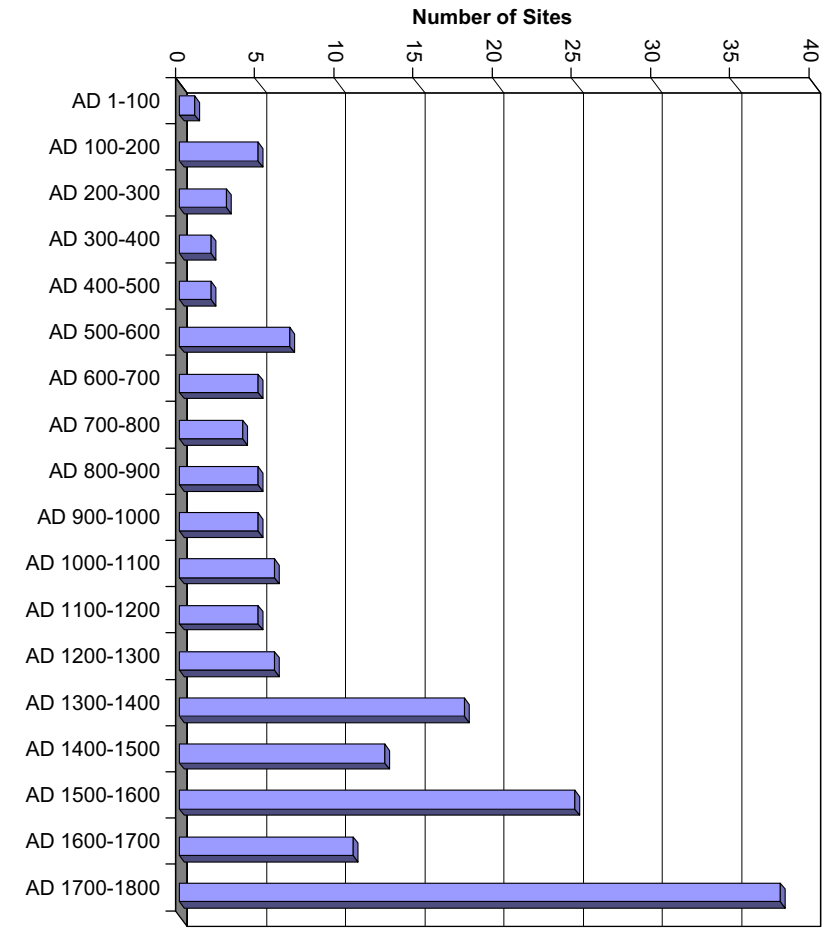

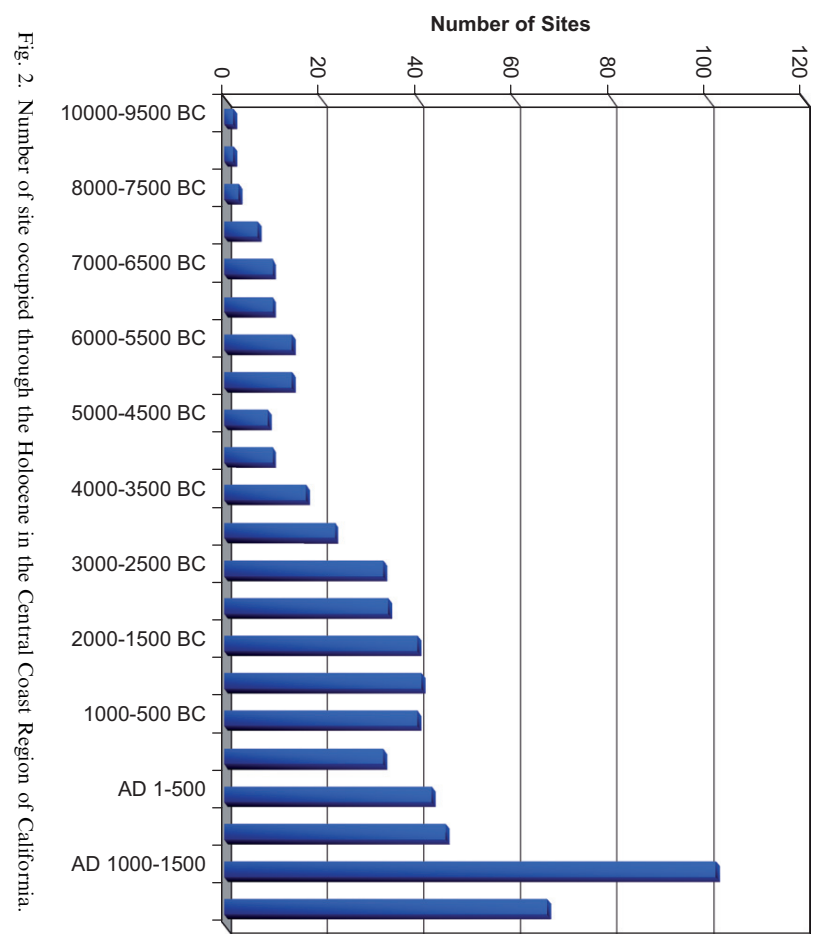


Table 1

Obsidian density from archaeological sites in the Central California coastal region before, during, and after the Medieval Climatic Anomaly

\begin{tabular}{|c|c|c|c|}
\hline Site & $\begin{array}{l}\text { Excavation volume screened } \\
\text { through } 3 \mathrm{~mm} \text { mesh }\left(\mathrm{m}^{3}\right)\end{array}$ & $\begin{array}{l}\text { Contemporaneous pieces of } \\
\text { obsidian }(N)\end{array}$ & $\begin{array}{l}\text { Obsidian } / \mathrm{m}^{3} \text { screened } \\
\text { through } 3 \mathrm{~mm} \text { mesh }\end{array}$ \\
\hline \multicolumn{4}{|c|}{$3500 \mathrm{cal} \mathrm{B.C.—cal} \mathrm{A.D.} 1000$ (pre-MCA) } \\
\hline CA-MNT-1228 & 1.6 & 1 & 0.40 \\
\hline CA-MNT-73 & 20.9 & 94 & 4.49 \\
\hline CA-MNT-569 A & 1.9 & 4 & 2.11 \\
\hline CA-MNT-63 & 3.2 & 19 & 5.93 \\
\hline CA-MNT-332 & 0.7 & 5 & 7.01 \\
\hline CA-MNT-521 & 3.2 & 32 & 10.00 \\
\hline CA-MNT-519 & 1.0 & 2 & 2.00 \\
\hline CA-MNT-1918 & 0.8 & 1 & 1.25 \\
\hline CA-SLO-267 & 7.0 & 6 & 0.86 \\
\hline Total (mean) & 40.3 & 164 & $(4.06)$ \\
\hline \multicolumn{4}{|c|}{ cal A.D. $1000-1250$ (MCA) } \\
\hline CA-MNT-1233 & 3.4 & 0 & 0.00 \\
\hline CA-SLO-9 & 23.7 & 26 & 1.09 \\
\hline Total (mean) & 27.1 & 0 & $(1.04)$ \\
\hline \multicolumn{4}{|c|}{ cal A.D. $1250-1769$ (post-MCA) } \\
\hline CA-MNT-1223 & 13.4 & 1 & 0.07 \\
\hline CA-MNT-1227 & 3.8 & 0 & 0.00 \\
\hline CA-MNT-1235 & 2.4 & 0 & 0.00 \\
\hline CA-MNT-1236 & 2.0 & 0 & 0.00 \\
\hline CA-MNT-1277/H & 5.0 & 0 & 0.00 \\
\hline CA-MNT-1942 & 8.2 & 0 & 0.00 \\
\hline CA-MNT-910 & 6.5 & 0 & 0.00 \\
\hline CA-MNT-1748/H & 16.1 & 2 & 0.13 \\
\hline CA-MNT-1770 & 8.0 & 1 & 0.13 \\
\hline CA-MNT-1942 & 8.2 & 0 & 0.00 \\
\hline Total (mean) & 73.6 & 4 & $(0.05)$ \\
\hline
\end{tabular}

Sources: Jones (2003) and Jones and Haney (2005).

Table 2

Radiocarbon results from CA-SLO-9

\begin{tabular}{|c|c|c|c|c|c|c|}
\hline Unit & Specimen no. & Laboratory no. & Depth $(\mathrm{cm})$ & Shell species & Conventional $14 \mathrm{C}$ age & $\begin{array}{l}\text { Calibrated age B.C. } 1 \\
\text { sigma }(\Delta R=290+35)\end{array}$ \\
\hline 1 & $1-2 \mathrm{a}$ & Beta-199103 & $80-90$ & Mytilus & $1720 \pm 40$ & A.D. 920 (990) 1030 \\
\hline 4 & $4-19 b$ & Beta-198050 & $10-20 \mathrm{a}$ & Mytilus & $1510 \pm 80$ & A.D. 1074 (1203) 1282 \\
\hline 4 & $4-4 a$ & Beta-199104 & $30-40$ & Mytilus & $1610 \pm 40$ & A.D. 1030 (1060) 1160 \\
\hline 4 & $4-5 \mathrm{a}$ & Beta-199105 & $30-40$ & Mytilus & $1470 \pm 40$ & A.D. 1190 (1240) 1290 \\
\hline 4 & $4-68 b$ & Beta-198051 & $70-80$ & Mytilus & $1570 \pm 60$ & A.D. 1043 (1126) 1214 \\
\hline 5 & $5-12 b$ & Beta-198052 & $10-20 \mathrm{a}$ & Balanus & $1670 \pm 80$ & A.D. 952 (1027) 1109 \\
\hline 5 & $5-59 b$ & Beta-198053 & $80-90$ & Mytilus & $1510 \pm 80$ & A.D. 1074 (1203) 1282 \\
\hline
\end{tabular}

accounted for only $4.4 \%$ (NISP $=6$ ) of the assemblage which contrasts strongly with most earlier and later deposits in the region (see Jones, 2003). Fish remains were also abundant (Table 4) although their density was less than at some earlier sites in the area (see Jones and Kennett, 1999; Jones and Ferneau, 2002a). The site's artifact assemblage showed a high frequency of fishing equipment, including circular shell fishhooks, and notched stone line weights (Fig. 4, Table 5). Oxygen isotope analysis of the terminal growth increment of mussel shells indicate that site inhabitants collected mussels during all seasons (Kennett and Bottman, 2006) from which it can be inferred that the site was used on a year-round basis. While the CA-SLO-9 finds do not constitute unequivocal proof for the influence of drought on this region's Native societies, they are consistent with a population tethered to one location for much the year with subsistence focused on marine resources in the face of an impoverished terrestrial environment. 
Table 3

Economically significant bird and mammal remains from CA-SLO-9

\begin{tabular}{|c|c|c|c|c|c|}
\hline Taxon & Common Name & NISP & $\%$ NISP & MNI & $\% \mathrm{MNI}$ \\
\hline \multicolumn{6}{|l|}{ Terrestrial mammals } \\
\hline Canis sp. & Dog/Coyote & 14 & 10.2 & 12 & 10.7 \\
\hline Lepus californicus & Jack rabbit & 1 & 0.7 & 1 & 0.9 \\
\hline Lynx rufus & Bobcat & 1 & 0.7 & 1 & 0.9 \\
\hline Mephitis mephitis & Stripped skunk & 1 & 0.7 & 1 & 0.9 \\
\hline Neotoma sp. & Woodrat & 12 & 8.8 & 6 & 5.4 \\
\hline Odocoileus hemionus & Black-tailed deer & 6 & 4.4 & 3 & 2.7 \\
\hline Procyon lotor & Raccoon & 2 & 1.5 & 2 & 1.8 \\
\hline Sylvilagus audubonii & Cottontail rabbit & 12 & 8.8 & 10 & 8.9 \\
\hline Sylvilagus bachmani & Brush rabbit & 3 & 2.2 & 2 & 1.8 \\
\hline \multirow[t]{2}{*}{ Sylvilagus sp. } & Rabbit & 22 & 16.1 & 17 & 15.2 \\
\hline & Subtotal & 74 & 54.0 & 55 & 49.1 \\
\hline \multicolumn{6}{|l|}{ Marine mammals } \\
\hline Callorhinus ursinus & Northern fur seal & 1 & 0.7 & 1 & 0.9 \\
\hline Enhydra lutris & Sea otter & 18 & 13.1 & 18 & 16.1 \\
\hline Phoca vitulina & California harbor seal & 2 & 1.5 & 2 & 1.8 \\
\hline \multirow[t]{2}{*}{ Zalophus californianus } & California sea lion & 1 & 0.7 & 1 & 0.9 \\
\hline & Subtotal & 22 & 16.1 & 22 & 19.6 \\
\hline \multicolumn{6}{|l|}{ Birds } \\
\hline Anser albifrons, cf. & White fronted goose & 1 & 0.7 & 1 & 0.9 \\
\hline Diomedea immutabilis & Laysan albatross & 1 & 0.7 & 1 & 0.9 \\
\hline Fratercula cirrhata & Tufted puffin & 1 & 0.7 & 1 & 0.9 \\
\hline Gavia sp. & Loons & 1 & 0.7 & 1 & 0.9 \\
\hline Mimus polyglottos & Northern mockingbird & 1 & 0.7 & 1 & 0.9 \\
\hline Phalacrocorax sp. & Cormorants & 30 & 21.9 & 26 & 23.2 \\
\hline Ptychoramphus aleuticus & Cassin's auklet & 2 & 1.5 & 2 & 1.8 \\
\hline \multirow[t]{3}{*}{ Uria aalge } & Common murre & 4 & 2.9 & 2 & 1.8 \\
\hline & Subtotal & 41 & 29.9 & 35 & 31.3 \\
\hline & Total & 137 & 100.0 & 112 & 100.0 \\
\hline
\end{tabular}

NISP $=$ number of specimens identified to the genus level or better excluding intrusive, ground burrowing rodents; MNI = minimum number of individuals caluculated by unit/level. Source: Codding and Jones (2006).

In general, the Medieval droughts hypothesis emphasizes the abrupt character of Late Period settlement and assemblage changes, and the fact that many developments, including decreased inter-regional exchange (marked by lower frequencies of obsidian), do not seem consistent with linear adaptive progress or progressive social evolution. Further, ethnohistoric accounts suggest that Late Period and contact-era populations consisted of small, mobile groups with some measure of sociopolitical complexity, although not necessarily greater than that of the societies that came before. The notion of de-intensification has been used to characterize the Late Period relative to the terminal Middle Period (Jones and Ferneau, 2002b) and to counter a widespread assumption that the Late Period represented the pinnacle of prehistoric population density, sociopolitical complexity, and subsistence intensity.

\subsection{Mojave Desert}

Because the Mojave Desert is so arid, it has long been assumed that prehistoric people would have been noticeably affected by any variation in its climate (Antevs, 1948).
Following early proposals by Sutton (1991), Jones et al. (1999) produced evidence for decreased use of the Mojave during the Medieval period, but not a full-scale abandonment. Since then, events transpiring in the Mojave Desert during the MCA have been heavily debated. Sutton et al. (2007) concluded the MCA was coincident with a number of culture changes including a decline of large villages, and a decrease in population density. They believe that conditions became so unfavorable that few people remained in much of the Mojave during the MCA. On the other hand, Basgall et al. (1988) and McGuire and Hall (1988) point to evidence for continuing human presence in the Mojave during the Medieval Period. In the face of such evidence, Sutton et al. (2007) suggest that rather than abandonment, there may have been merely a population shift to a different settlement pattern, with people aggregating in more compact settlement units and taking better advantage of diminishing resources.

More recently Gardner (2006) completed a systematic evaluation of the possible effects of Medieval droughts on Mojave populations and concluded that influence of drought is apparent but not unambiguous. For the Rose 
Table 4

Summary of fish remains from CA-SLO-9

\begin{tabular}{|c|c|c|c|c|c|}
\hline Taxon & Common name & NISP & $\%$ NISP & MNI & Wt. \\
\hline Atherinopsidae & Silversides & 22 & 3 & 3 & 0.23 \\
\hline Clinidae & - & 2 & 0 & 0 & 0.02 \\
\hline Clupeidae & Herrings & 17 & 3 & 1 & 0.13 \\
\hline Cottidae & - & 1 & 0 & 0 & 0.01 \\
\hline Elasmobran-chiomorphi & Shark & 1 & 0 & 1 & 0.03 \\
\hline Embiotocidae & Surfperches & 40 & 6 & 12 & 1.29 \\
\hline Gillichthys mirabilis & Longjaw Mudsucker & 1 & 0 & 1 & 0.01 \\
\hline Gibbonsia sp. & Crevice Kelpfish & 2 & 0 & 1 & 0.05 \\
\hline Hexagrammos sp. & Kelp Greenling & 2 & 0 & 2 & 0.12 \\
\hline Merluccius productus & Pacific hake & 2 & 0 & 2 & 0.08 \\
\hline Ophiodon elongatus & Lingcod & 1 & 0 & 2 & 0.16 \\
\hline Oxyjulis californica & Senorita & 46 & 7 & 31 & 2.06 \\
\hline Porichthys notatus & Plainfin Midshipman & 2 & 0 & 2 & 0.02 \\
\hline Sardinops sagax & Pacific Sardine & 6 & 1 & 5 & 0.07 \\
\hline Sciaenidae & Croakers & 1 & 0 & 1 & 0.01 \\
\hline Scorpaenichthys marmoratus & Cabezon & 192 & 29 & 118 & 37.2 \\
\hline Scorpaeniformes & - & 1 & 0 & 0 & 0.04 \\
\hline Sebastes sp. & Rockfishes & 292 & 44 & 177 & 32.96 \\
\hline Stichaeidae & Pricklebacks/Monkeyface & 33 & 5 & 14 & 2.1 \\
\hline Triakidae & Hound Shark & 1 & 0 & 0 & 0.89 \\
\hline Xiphister sp. & Black Prickleback & 5 & 1 & 5 & 0.4 \\
\hline \multirow[t]{2}{*}{ Actinopterygii } & Bone Fragments & 1520 & - & 1 & 71.45 \\
\hline & Total & 2190 & - & 379 & 149.33 \\
\hline
\end{tabular}

NISP = number of identified specimens; MNI = minimum number of individuals calculated by unit/level. Source: Codding and Jones (2006).

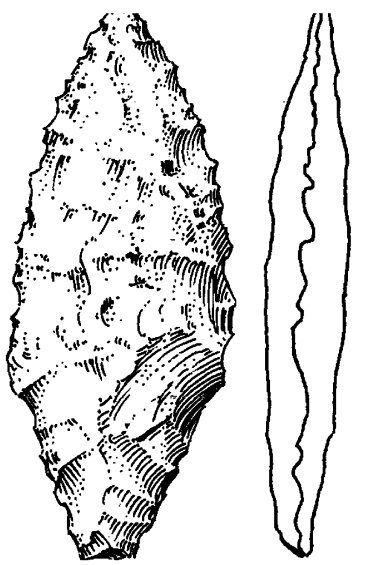

CONTRACTING-STEMMED

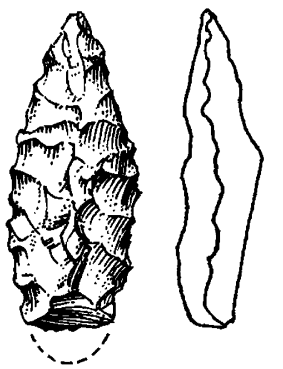

SMALL LEAF SHAPED

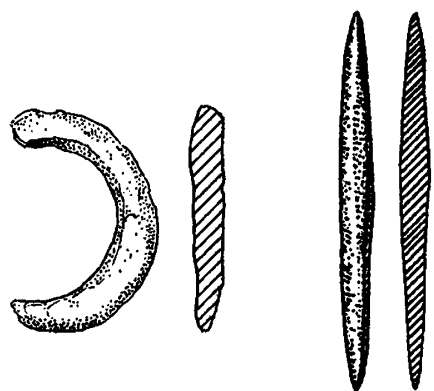

CIRCULAR SHELL FUSHHOOK
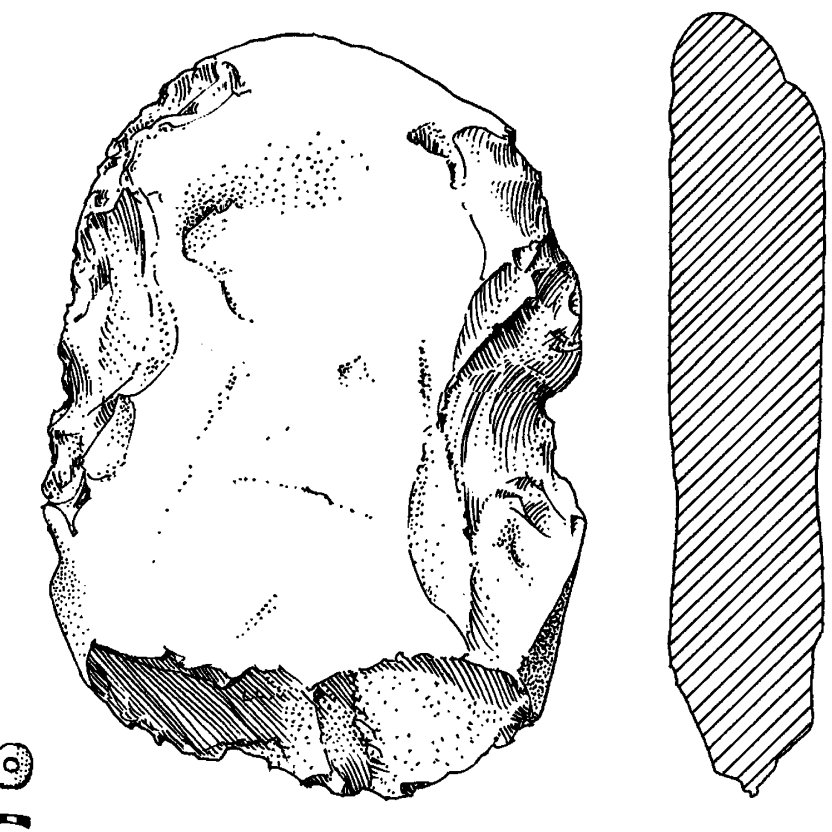

NOTCHED STONE (SINKER)

\section{OLIVELLA K OLIVELLA G2 OLIVELLA G1 \\ CUPPED SAUCER SAUCER \\ BEADS BEADS BEADS}

$\mathrm{cm}$

Fig. 4. Artifacts from CA-SLO-9, Montaña de Oro State Park, San Luis Obispo County (drawn by Rusty van Rossmann). 
Table 5

Summary of formal artifact assemblage from CA-SLO-9

\begin{tabular}{|c|c|c|}
\hline Artifact & & Number \\
\hline \multicolumn{3}{|l|}{ Shell beads } \\
\hline Olivella G2 normal saucer & & 16 \\
\hline Olivella G1 tiny saucer bead & & 1 \\
\hline Olivella $K 1$ cupped bead & & 2 \\
\hline \multirow[t]{2}{*}{ Limpet ring } & & 45 \\
\hline & Subtotal & 64 \\
\hline \multicolumn{3}{|l|}{ Stone beads } \\
\hline \multirow[t]{2}{*}{ Steatite disk } & & 1 \\
\hline & Subtotal & 1 \\
\hline \multicolumn{3}{|l|}{ Projectile points } \\
\hline Contracting-stemmed & & 11 \\
\hline Small leaf-shaped & & 7 \\
\hline Double side-notched & & 1 \\
\hline \multirow[t]{2}{*}{ Large side-notched } & & 1 \\
\hline & Subtotal & 20 \\
\hline \multicolumn{3}{|l|}{ Other flaked stone } \\
\hline Drills & & 1 \\
\hline Reamers & & 2 \\
\hline \multirow[t]{2}{*}{ Notched stones (line or net weights) } & & 15 \\
\hline & Subtotal & 18 \\
\hline \multicolumn{3}{|l|}{ Ground and battered stone } \\
\hline Battered cobbles & & 12 \\
\hline \multirow[t]{2}{*}{ Pitted stone } & & 1 \\
\hline & Subtotal & 13 \\
\hline \multicolumn{3}{|l|}{ Non-bead shell artifacts } \\
\hline Circular shell fishhooks & & 9 \\
\hline Fishhook blanks & & 1 \\
\hline \multirow[t]{2}{*}{ Asphaltum-covered shell } & & 1 \\
\hline & Subtotal & 11 \\
\hline \multicolumn{3}{|l|}{ Bone tools } \\
\hline Awls & & 2 \\
\hline \multirow[t]{3}{*}{ Bi-pointed object } & & 1 \\
\hline & Subtotal & 3 \\
\hline & Grand total & 130 \\
\hline
\end{tabular}

Spring Period (cal A.D. 200-1100) she reported increased use of lagomorphs and other small game, consistent with an arid, non-productive environment. Later, between the late Rose Spring and early Late Prehistoric periods, a reduced size and number of habitation sites and a decreased focus on lagomorphs was apparent. Other recent interpretations (Hildebrandt and Ruby, 2006) suggest that dietary changes were driven strictly by population-based intensification. Also complicating interpretations of the Mojave record are recent suggestions that exploitation of rabbits is not a sign of subsistence intensification or pursuit of a low-ranked taxon (McGuire and Hildebrandt, 1994; Hildebrandt and McGuire, 2002). More significantly, Gardner (2006, p. 371) confirmed that the system of obsidian production and exchange that was an intrinsic component of prehistoric Mojave adaptations collapsed at the end of the Rose Springs Period, as Gilreath and Hildebrandt suggested in 1997.

\subsection{San Francisco Bay and the Central Valley}

The Medieval droughts have not been a major focus of research in the San Francisco Bay area where a rich, diverse estuarine resource base was available from midHolocene onward. Some arguments have been made for a settlement shift at the end of the Middle Period (ca. A.D. 1050) (e.g. Jones, 1992, p. 12; Lightfoot and Luby, 2002, pp. 276-277), but recent research (Milliken et al., 2007) suggests that such a shift dates to pre-MCA times. Recent findings do show a significant increase in sites after ca. cal A.D. 1250 (Fig. 5), consistent with trends on the Central Coast. In the Central Valley, where populations were clustered along the Sacramento and San Joaquin rivers and their tributaries, Rosenthal et al. (2007) posit a significant cultural transition at cal A.D. 1000, but report no obvious signs of drought or its cultural effects.

\subsection{Northern California}

In arid northeastern California, the precise relationships between late Holocene climatic variability and archaeologically observed cultural changes remain poorly understood. In a recent review, McGuire (2007) notes that cal A.D. 1000 was a time of instability and upheaval, but is non-committal on whether these changes were induced by climatic change, increases in population density, or other factors. In the Northwest, Hildebrandt (2007) notes that obsidian production at Clear Lake quarries and adjacent areas collapsed after cal. A.D. 800 and that later cultural patterns are poorly represented. Increasing sociopolitical complexity through the late Holocene is relatively welldocumented north of Cape Mendocino, but in the southern North Coast Ranges, Hildebrandt (2007) reports evidence for decentralization of population, smaller sociopolitical groups and more mobile settlement systems after ca. cal A.D. $800-1000$ although he fails to attribute these shifts directly to the effects of the drought. Elsewhere, McGuire and Hildebrandt (2005) attribute cultural changes in western North America ca. cal A.D. 1000 to certain inherent inefficiencies associated with earlier hunting strategies.

\section{Health and violence: osteological signs of crisis}

Correlations between the Medieval droughts, health problems, and violence were significant components of ideas put forth in the 1990s about the effects of the MCA on California's Native people (Fischman, 1996; Raab and Larson, 1997). Using osteological data collected by Lambert and Walker from the Santa Barbara Channel (Walker, 1989; Walker and Lambert, 1989; Lambert and Walker, 1991; Lambert, 1993), Raab and Larson (1997) 


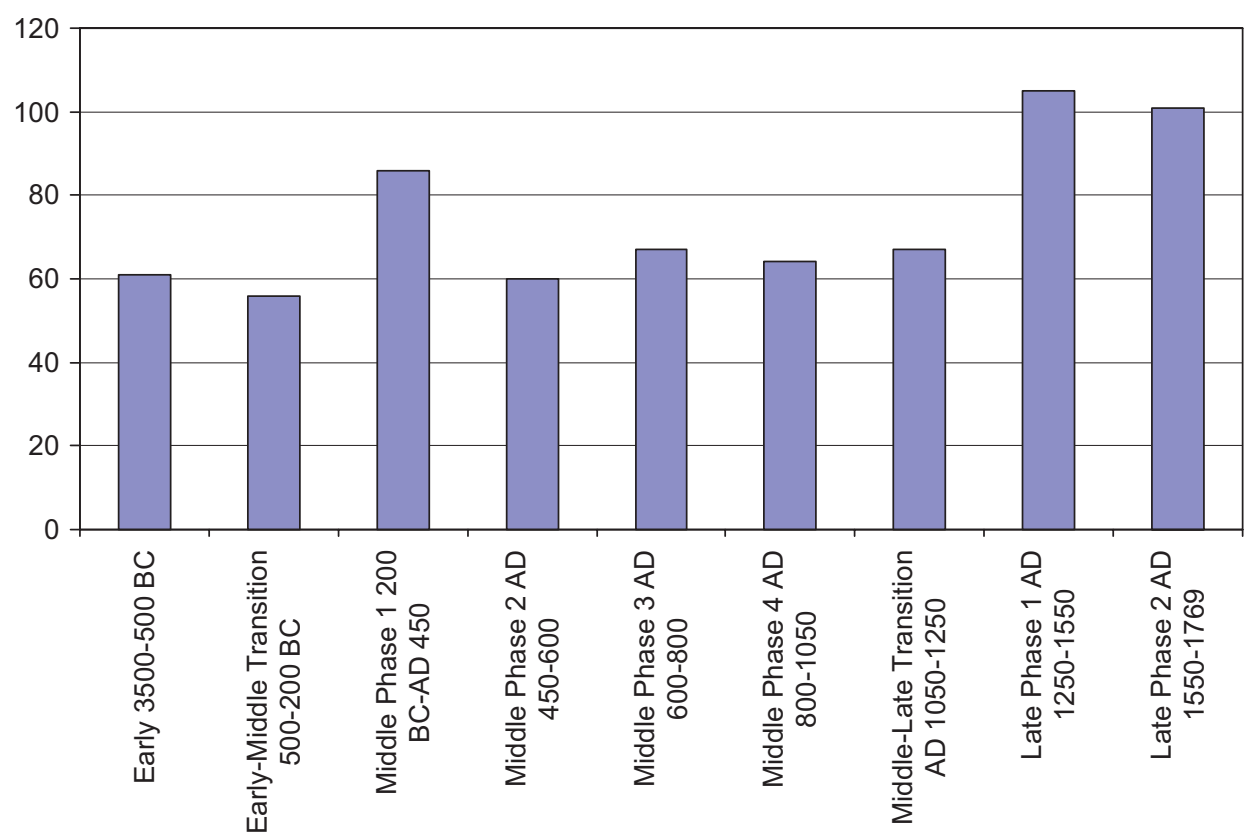

Fig. 5. Number of Sites occupied per phase in the San Francisco Bay Area from 3500 cal B.C. to cal A.D. 1769 (from Milliken et al. 2007, p. 108).

argued that peaks in cribra orbitalia, periosteal lesions (caused by infectious diseases), and cranial fractures (caused by inter-group conflict) were evident during the MCA as a result of the types of social crises that Moratto et al. (1978) proposed earlier. While data supporting this argument were fairly compelling, it must also be recognized that chronological resolution was far from perfect and that peaks in violence and poor health were ascribed to a broad period between ca. A.D. 300 and 1150. Again, this long interval is not synchronous with the MCA as it was defined by Stine, but it does support Kennett's (2005) view that droughts and related violence gradually increased in the Santa Barbara Channel from ca. cal A.D. 450 and culminated ca. cal A.D. 1150, rather than beginning suddenly after cal A.D. 800. As in the Sierra Nevada, however, it must be noted that Lambert relied out of necessity on a fairly coarse-grained chronology which could contribute to the perception of a prolonged period of stress.

The Southern Bight study has been followed by two relatively small analyses from central California that produced only modest evidence for drought-related health problems and/or increased violence. Weiss (2002) compared cortical thickness, age at death, and pathology/ trauma frequency between two cemetery populations in the San Joaquin Valley, one pre-dating the Medieval droughts (ca. 1000 cal B.C.-cal A.D. 200) and the other representing the MCA (ca. cal A.D. 800-1000). The pre-drought cemetery showed greater cortical thickness (healthier bones), slightly longer life spans, and fewer pathologies than the MCA-era remains but the study was based on an extremely small sample (cortical thickness, $N=64$ individuals; pathologies, $N=98$ ). More recently, Pilloud (2005, 2006) reported finding from a larger $(N=473)$ cemetery in the San Francisco Bay Area at CA-ALA-613/H where individuals were interred pre- $(1890$ cal B.C.-cal A. D. 800), post- (cal. A.D. 1350-1760), and during (cal. A.D. $800-1350)$ the MCA. Examining a wide range of dental and other skeletal signs of violence and/or health problems, she found that the overall health of the population was relatively stable as only carious lesions showed a peak among females during the MCA, which Pilloud interpreted as evidence of climatically induced dietary change. Signs of violence were relatively minor throughout the span of the site's use (11 individuals), contrasting with the Santa Barbara Channel.

A considerably larger and more significant evaluation of human skeletal remains from central California recently completed by one of us (Schwitalla) shows more compelling and substantive patterns. This study includes detailed information from 13,942 skeletons from 274 sites in the San Francisco Bay, Central Valley, Central Coast, and Central Sierra Nevada regions, and constitutes the single largest bioarchaeological analysis ever completed in California. As in the Santa Barbara Channel, bead-based chronological assignments were not exactly concordant with the dating of the MCA established by Stine, but in this instance they do provide for an exceptionally fine-grained evaluation of health, diet, and violence over the last 1500 years. Results of this extensive data compilation show a consistent bimodal pattern of increased violence and health problems during the early (cal A.D. 740-1010) and late (cal A.D. 1210-1390) MCA, with declines in between and after (Table 6). Dental caries, for example, were identified on $41 \%$ of the skeletons dating to the late MCA, as opposed to only $24 \%$ during the preceding period (cal A.D. 1010-1210) and only 7\% afterwards (cal A.D. 1390-1700). Likewise, enamel hypoplasia, bone fractures, 
Table 6

Osteological indices of health, diet, and violence from Central California cemetery populations dating to the late holocene (from Schwitalla 2007)

\begin{tabular}{|c|c|c|c|c|c|}
\hline Index & $\begin{array}{l}\text { Intermediate-Terminal } \\
\text { Middle Period } \\
\text { cal A.D. } 420-740 \\
(1530-1215 \mathrm{BP})\end{array}$ & $\begin{array}{l}\text { Late Middle Period } \\
\text { Early MCA } \\
\text { cal A.D. } 740-1010 \\
(1215-940 \text { BP) }\end{array}$ & $\begin{array}{l}\text { Middle/Late Period } \\
\text { Transition } \\
\text { Middle MCA } \\
\text { (Drought Hiatus) } \\
\text { cal A.D.1010-1210 } \\
(940-740 \text { BP) }\end{array}$ & $\begin{array}{l}\text { Late Period 1A-Late } \\
\text { Period 1B } \\
\text { Late MCA } \\
\text { cal A.D. } 1210-1390 \\
(740-560 \mathrm{BP})\end{array}$ & $\begin{array}{l}\text { Late Period } 1 \mathrm{C}-\text {-Late } \\
\text { Period } 2 \mathrm{~A}\end{array}$ \\
\hline Dental caries ${ }^{\mathrm{a}}$ & $19 \%$ & $20 \%(77)$ & $24 \%(251)$ & $41 \%(111)$ & $7 \%(144)$ \\
\hline $\begin{array}{l}\text { Enamel } \\
\text { hypoplasia }^{\text {b }}\end{array}$ & $6 \%(323)$ & $0 \%(69)$ & $9 \%(260)$ & $13 \%(119)$ & $3 \%(121)$ \\
\hline Anemia $^{c}$ & $5 \%(329)$ & $5 \%(75)$ & $4 \%(263)$ & $15 \%(143)$ & $22 \%(160)$ \\
\hline Fractures $^{\mathrm{d}}$ & $9 \%(293)$ & $11 \%(65)$ & $22 \%$ & $24 \%(107)$ & $13 \%(137)$ \\
\hline Disease $^{\mathrm{e}}$ & $14 \%$ & $20 \%(77)$ & $15 \%(265)$ & $28 \%(145)$ & $19 \%(160)$ \\
\hline Violence $^{\mathrm{f}}$ & $10 \%$ & $19 \%(64)$ & $12 \%(259)$ & $26 \%(115)$ & $15 \%(136)$ \\
\hline Mass burials ${ }^{\mathrm{g}}$ & $9 \%(365)$ & $9 \%(64)$ & $5 \%(736)$ & $10 \%(272)$ & $9 \%(499)$ \\
\hline
\end{tabular}

$\%=$ Prevalence of index in each sample population. $(N)=$ sample of individuals measured for each index and temporal phase. $(N)=$ total burials, not individuals for Mass Burial Index.

${ }^{a}$ Dental caries are tabulated for individuals 5 years of age or older with a minimum of 1-2 caries.

${ }^{b}$ Enamel Hypoplasia is tabulated for individuals 1.5 years of age or older with a minimum of one hypoplastic lesion.

${ }^{\mathrm{c}}$ Anemia represents either cribra orbitalia, porotic hyperostosis, or instances of both conditions for individuals 0.50 years of age or older.

${ }^{\mathrm{d}}$ Fractures = non-violent fracture/fractures are tabulated for individuals 12 years of age or older with a minimum of one ante or peri-mortem trauma incident, but not including any fracture commonly associated with vertebral osteophytosis, degenerative joint disease of the spine, etc. Fractures of vertebral bodies were tabulated only if they were in close association with other fractured elements indicating a likely episodic event for causation.

${ }^{\mathrm{e}}$ Disease $=$ specific and non-specific disease etiologies that result in reactive bone lesions classified as either periostitis, osteomyelitis or instances of both conditions tabulated for individuals 0.25 years of age or older with a minimum of one lesion per person.

${ }^{\mathrm{f}}$ Violence $=$ ante and peri-mortem blunt and sharp force trauma attributed to violent conflict is tabulated for individuals 12 years of age or older with a minimum of one incident per person. Forearm or "Parry Fracture" blunt force trauma is counted only if the injury includes fracturing of the proximal Ulna. Contextual indications of violence, such as a projectile point found in situ between two ribs for example are not included in the tabulation of this index.

${ }^{\mathrm{g}}$ Mass burials $=$ graves that contain two or more articulated individuals deemed to be contemporaneous in their interment.

lesions indicative of disease, signs of violence, and mass burials all show peak percentages during the late Medieval Climatic Anomaly. Only signs of anemia, representing cribra orbitalia and/or porotic hyperostosis increase after cal A.D. 1390. Overall, this study provides the most compelling evidence yet for punctuated increases in health problems and violence synchronous with the two intervals of drought defined by Stine (1994).

\section{Technological change and innovation}

One anticipated response to environmental problems is technological innovation, particularly the development of tools and/or weapons that would allow for greater quantities food to be obtained, processed and/or distributed. In general, the late Holocene was a time of technological change in California and determining the causes underlying the innovations is difficult. Whether new implements appeared as a result of drought-related demographic stress, population growth, simple diffusion, or some combination thereof is at best very unclear. Three major technologies show significant change during the late Holocene: pottery (which appeared for the first time in many areas), weapon systems (marked by the appearance of the bow and arrow), and watercraft (the emergence of the sewn plank canoe in the Chumash area). As discussed above, Arnold (1992a) linked increased use of the sewn plank canoe to environmental problems during the MCA, but the initial development of this craft actually took place earlier, probably between cal. A.D. 400 and 800 , and it cannot be realistically linked to the MCA. Ceramics of one form or another were present in Native California in extremely low quantities well before the MCA (see Drover 1975) but the appearance of ceramic vessels in significant quantities into areas like San Diego County (Gallegos, 2002, p. 35) dates almost precisely to the onset of the MCA (cal A.D. 800). Likewise the bow is thought to have appeared in western North America as early as cal A.D. 400 , but it did not become the dominant weapon in places like the Central Coast or the San Francisco Bay Area until between cal A.D. 1000 and 1250. Its arrival in the Santa Barbara Channel area ca. cal A.D. 500-600 is indicated by the initial occurrence of skulls with arrow points embedded in them and small punctures interpreted as arrow point wounds (Lambert, 1994). Both ceramics and the bow and arrow seem to have originated east of California, and their later appearance on the Pacific coast may reflect accelerated westward diffusion related to movement of people out of the Great Basin. While there is no direct connection between the technological advantages conveyed by these two technologies and the exigencies of drought, their spread may reflect widespread movements of people during the Medieval Period, with many abandoning the xeric interior in favor of the coast. 


\section{Summary}

A review of recent research from eight regions of California shows strong evidence for cultural changes during the MCA that appear to reflect responses to prolonged droughts by Native populations although patterns are neither as simple nor as straight-forward as previously suggested. In three regions, the Central Coast, San Francisco Bay Area, and the mainland of the Northern Bight, significant population increases are evident after cal A.D. 1300. In the Orange County/Gabrielino area, populations seem to have peaked at cal A.D. 1300 and declined thereafter. In the southern Sierra Nevada, the MCA is associated with a widespread, long-lived abandonment although this is one of several regions where developments seem to have begun earlier (ca. cal 500-600) than the date of cal A.D. 800 set by Stine (1994) as the beginning of the MCA. Strong cultural changes in the Santa Barbara area, San Diego County, and the southern Sierra Nevada also seem to have begun ca. cal A.D. 400-700. The contradictory nature of patterns on the Central Coast versus Orange County should not be overlooked, but the population increases after ca. A.D. 1300 may reflect widespread movements of people to the coast from the interior.

One of the strongest patterns suggesting the influence of Medieval droughts is settlement disruption which is apparent on the mainland of Santa Barbara coast, the Central Coast, and on nearly all of the northern and southern Channel Islands where there is little evidence for continuing occupation of the same locations before, during, and after the MCA. Population trends in the arid Mojave Desert, however, remain unclear, owing to poor chronological resolution. Some authors (e.g. Gardner, 2006; Sutton et al., 2007) suggest that the droughts caused settlement shifts while others (e.g., Basgall et al. 1988) disagree.

Subsistence residues from the mainland and islands of central and southern California show no signs of reduced marine productivity during the MCA, and several sites show populations focused on fish and other marine foods. Faunal remains from one mainland site (CA-SLO-9) suggest that deer populations were depressed during the MCA and that people relied more heavily on fish, shellfish, sea birds, and rabbits. However, none of these areas show anomalously intensive or exclusive focus on marine foods during the MCA - except on the islands where subsistence was always marine-focused in the absence of terrestrial game animals.

Osteological studies show two different patterns as the Santa Barbara Channel shows a gradual, incremental increase in violence and disease from cal A.D. 450-1150, while a large study in central California shows punctuated, bi-modal increases in health problems and violence synchronous with the two intervals of drought during Stine's (1994) MCA. The correlation between the central California osteological record and Stine's characterization of the MCA provides extremely compelling support for the Medieval droughts hypothesis.

Deterioration of long-distance obsidian trade which began to decline ca. cal A.D. $800-1250$ also provides strong evidence for the widespread effects of Medieval droughts. Signs of decreased production have been identified at sources both in the North Coast Ranges and eastern California, at the same time that increases in localized bead exchange are apparent in the Central Coast region, the Santa Barbara Channel, and the San Francisco Bay and San Diego areas. This deterioration is well supported by obsidian data from the Central Coast where trade goods stopped arriving ca. A.D. 1250. Jackson and Ericson (1994) suggested that such a trend was the culmination of a long-term, incremental progression in which more and more commodities were traded over shorter distances in Native California. The obsidian record as it is presently documented, however, shows an abrupt decline throughout much of California not an incremental one.

Most of the technological changes that mark the late Holocene in Native California seem unrelated to the MCA inasmuch as several important innovations (e.g., pottery, the bow and arrow, and the sewn-plank canoe) predate the MCA. Nonetheless, the rapid spread of pottery and the bow after cal A.D. 800 in some areas may reflect widespread movements of people related to the Medieval droughts.

\section{Conclusions}

The case for human response to droughts during the MCA is ultimately reliant on temporal correlations, which in the end cannot prove causality. At present there are two different correlations being advanced for the MCA: one based on Stine's original view of the period as punctuated, anomalous, and relatively brief, and Kennett's (2005, pp. 68-71) view of a long period of cool seas and general aridity (ca. cal A.D. 450-1350) that culminated in extreme droughts between cal A.D. 950 and 1150 and A.D. 1250-1350. The punctuated view is supported by the occurrence of seemingly abrupt cultural change in the Central Coast and San Francisco Bay regions, by widespread and rapid deterioration of long distance obsidian trade, and especially by new bioarchaeological evidence for increased health problems and escalation in violence in Central California. In many other regions, cultural changes can be traced back to cal. A.D. 400-700 (e.g., Sierra Nevada, Northern Channel Islands, Orange County). Kennett (2005) suggests that cal A.D. 450 marked the beginning of an extended period of extremely unstable climate which he felt was a major contributing factor to the cultural changes that began at about that time. Thus, at present there exist two slightly different interpretations of the MCA, its duration, and nature of its influence on Native populations. 
Overall, it is nearly impossible to interpret the late Holocene archaeological record of California without recognizing the period between cal A.D. 800 and 1300 as unusual. Settlement changes, site abandonments, and rapid spread of new technologies almost unequivocally reflect widespread movements of people. Osteological studies show changes in diet and increased health problems and escalating violence although these responses were regionally varied. The deterioration of long-distance exchange suggests that inter-group relations destabilized and it remains likely that inter-group conflicts increased in some areas, as suggested by both the earlier studies in the 1990s in the Santa Barbara Channel and more recent osteological findings from central California. More research needs to be completed with better temporal resolution in order to determine whether the MCA is best characterized as a period of abrupt and anomalous climatic events that caused rapid social deterioration, or whether it was a prolonged period of environmental instability that led to incremental increases in demographic problems. It is also possible that these alternative conceptualizations reflect inter-regional variation in the local effects of drought and the responses of human populations. Such alternatives need to be evaluated in future research.

\section{Acknowledgments}

Funding for research at CA-SLO-9 was provided by California Department of Parks and Recreation. We thank Elise Wheeler for her help in facilitating that research. We also thank Douglas Kennett for providing valuable comments on an earlier draft of this paper and Brian Codding for his help with the map in Fig. 1. Artifact illustrations were provided by Rusty van Rossmann.

\section{References}

Antevs, E., 1948. Climatic changes and pre-white man. University of Utah Bulletin 38, 168-191.

Antevs, E., 1955. Geologic-climatic dating in the west. American Antiquity 20, 317-335.

Arnold, J.E., 1991. Transformation of a regional economy: sociopolitical evolution and the production of valuables in southern California. Antiquity 65, 953-962.

Arnold, J.E., 1992a. Complex hunter-gatherer-fishers of prehistoric California: chiefs, specialists, and maritime adaptations of the channel islands. American Antiquity 57, 60-84.

Arnold, J.E., 1992b. Cultural disruption and the political economy in Channel Islands prehistory. In: Jones, T.L. (Ed.), Essays on the Prehistory of Maritime California, vol. 10. Center for Archaeological Research at Davis, pp. 129-146.

Arnold, J.E., 1993. Labor and the rise of complex hunter-gatherers. Journal of Anthropological Archaeology 12, 75-119.

Arnold, J.E., 1995. Transportation innovation and social complexity among maritime hunter-gatherer societies. American Anthropologist 97, 733-747.

Arnold, J.E., 2001a. Social evolution and the political economy in the northern Channel Islands. In: Arnold, J.E. (Ed.), The Origins of a Pacific Coast Chiefdom: The Chumash of the Channel Islands. University of Utah Press, Salt Lake City, pp. 287-296.
Arnold, J.E. (Ed.), 2001b. The Origins of a Pacific Coast Chiefdom: The Chumash of the Channel Islands. University of Utah Press, Salt Lake City.

Arnold, J.E., Bernard, J., 2005. Negotiating the coasts: status and the evolution of boat technology in California. World Archaeology 37, $109-131$.

Arnold, J.E., Graesch, A.P., 2001. The evolution of specialized shellworking among the Island Chumash. In: Arnold, J.E. (Ed.), The Origins of a Pacific Coast Chiefdom: The Chumash of the Channel Islands. University of Utah Press, Salt Lake City, pp. 71-112.

Arnold, J.E., Tissot, B., 1993. Measurement of significant marine paleotemperature variation using Black Abalone Shells from Middens. Quaternary Research 39, 390-394.

Basgall, M.E., 1987. Resource intensification among hunter-gatherers: acorn economies in prehistoric California. Research in Economic Anthropology 9, 21-52.

Basgall, M.E., 1999. Comment on environmental imperatives reconsidered: demographic crises in western North America during the Medieval Climatic Anomaly. In: Jones, T.L., Brown, G.M., Raab, L.M., McVickar, J.L., Spaulding, W.G., Kennett, D.J., York, A., Walker, P.L. (Eds.), Current Anthropology, vol. 40, pp. 157-158.

Basgall, M.E., Hall, M.C., 1992. Fort Irwin archaeology: emerging perspectives on Mojave Desert prehistory. Society for California Archaeology Newsletter 26 (5), 1-7.

Basgall, M.E., Hall, M.C., McGuire, K.R., 1988. The Late Holocene Archaeology of Drinkwater Basin, Fort Irwin, San Bernardino, California. Report on file, San Bernardino County Archaeological Information Center, San Bernardino County Museum, Redlands.

Baumhoff, M.A., Heizer, R.F., 1965. Postglacial climate and archaeology in the Desert West. In: Wright Herbert, H., Fray David, G. (Eds.), The Quaternary of the United States. Princeton University Press, Princeton, pp. 697-707.

Bernard, J.L., 2001. The origins of open-ocean and large species fishing in the Chumash Region of Southern California. Unpublished Master's Thesis, Department of Anthropology, University of California, Los Angeles.

Bettinger, R.L., 1991. Aboriginal occupation at high-altitude: Alpine villages in the white mountains of Eastern California. American Anthropologist 93 (3), 656-679.

Bettinger, R.L., 1999. Comment on environmental imperatives reconsidered: demographic crises in Western North America during the Medieval Climatic Anomaly. In: Jones, T.L., Brown, G.M., Raab, L.M., McVickar, J.L., Spaulding, W.G., Kennett, D.J., York, A., Walker, P.L. (Eds.), Current Anthropology, vol. 40, pp. 157-158.

Broughton, J.M., Bayham, F.E., 2003. Showing off, foraging models, and the ascendance of large-game hunting in the California middle archaic. American Antiquity 68, 783-789.

Byers, D.A., Broughton, J.M., 2004. Holocene environmental change, artiodactyl abundances, and human hunting strategies in the Great Basin. American Antiquity 69, 235-256.

Byrd, B.F., 1998. Harvesting the littoral landscape during the late Holocene: new perspectives from northern San Diego County. Journal of California and Great Basin Anthropology 20, 195-218.

Byrd, B.F., Reddy, S.N., 2002. Late Holocene adaptations along the northern San Diego coastline: new perspectives on old paradigms. In: Erlandson, J., Jones, T.L. (Eds.), Catalysts to Complexity: Late Holocene of the California Coast. Cotsen Institute of Archaeology, University of California, Los Angeles, pp. 41-62.

Byrne, R., 1979. Commentary on "archaeology and california's climate". Journal of California and Great Basin Anthropology 1, 196-200.

Christenson, L.E., 1992. The late prehistoric Yuman settlement and subsistence system: coastal adaptation. In: Jones, T. (Ed.), Essays on the Prehistory of Maritime California, vol. 10. Center for Archaeological Research at Davis Publications, pp. 217-230.

Cleland, J.H., Spaulding, W.G., 1992. An alternative perspective on Mojave Desert prehistory. Society for California Archaeology Newsletter $26(6), 1-6$. 
Codding, B.F., Jones, T.L., 2006. The Middle-Late Transition on the Central California Coast: Archaeological Salvage at CA-SLO-9, Montaña de Oro State Park, San Luis Obispo County, California. Department of Social Sciences, California Polytechnic State University, San Luis Obispo. Prepared for California Department of Parks and Recreation, San Simeon.

Colten, R.H., 1995. Faunal exploitation during the middle to late period transition on Santa Cruz Island, California. Journal of California and Great Basin Anthropology 17, 93-120.

Colten, R.H., 2001. Ecological and economic analysis of faunal remains from Santa Cruz Island. In: Arnold, J.E. (Ed.), The Origins of a Pacific Coast Chiefdom: The Chumash of the Channel Islands. University of Utah Press, Salt Lake City, pp. 199-220.

Cook, E.R., Woodhouse, C.A., Eakin, C.M., Meko, D.M., Stahle, D., 2004. Long-term aridity changes in the Western United States. Science 306, 1015-1018.

deMenocal Peter, B., 2001. Cultural responses to climate change during the Late Holocene. Science 292, 667-673.

Douglass, A.E., 1929. The secrets of the southwest solved by talkative tree rings. National Geographic 54, 737-770.

Drover, C., 1975. Early ceramics from Southern California. Journal of California Anthropology 2, 101-107.

Erlandson, J.M., 1993. Summary and conclusions. In: Gerber, J.L. (Ed.), Archaeological Investigations at CA-SBA-1731: A Transitional Middle-to-Late Period Site on the Santa Barbara Channel. Dames and Moore, Santa Barbara, CA.

Erlandson, J.M., Rick, T.C., 2002. Late Holocene cultural developments along the Santa Barbara Coast. In: Erlandson, J.M., Jones, T.L. (Eds.), Catalysts to Complexity: Late Holocene Societies of the California Coast. Cotsen Institute of Archaeology, University of California, Los Angeles, pp. 166-182.

Fagan, B.M., 2004. The Long Summer: How Climate Changed Civilization. Basic Books, New York.

Fischman, J., 1996. California social climbers: low water prompts high status. Science 272, 811-812.

Gallegos, D.R., 2002. Southern California in transition: Late Holocene occupation of southern San Diego county. In: Erlandson, J.M., Jones, T.L. (Eds.), Catalysts to Complexity: Late Holocene Societies of the California Coast. Cotsen Institute of Archaeology, University of California, Los Angeles, pp. 27-40.

Gamble, L.H., 2005. Culture and Climate: reconsidering the effect of palaeoclimatic variability among Southern California hunter-gatherer societies. World Archaeology 37, 92-108.

Gamble, L.H., Russell, G.S., 2002. A view from the Mainland: Late Holocene cultural developments among the Ventureno Chumash and the Tongva. In: Erlandson, J.M., Jones, T.L. (Eds.), Catalysts to Complexity: Late Holocene Societies of the California Coast. Cotsen Institute of Archaeology, University of California, Los Angeles, pp. $101-126$

Gardner, J.K., 2006. The potential impact of the Medieval Climatic Anomaly on human populations in the Western Mojave Desert Unpublished Ph.D. Dissertation, Department of Anthropology, University of Nevada, Las Vegas.

Gilreath, A., 1995. Archaeological evaluations of thirteen sites for the Ash Creek Project, Inyo County, California. Far Western Anthropological Research Group, Davis. Prepared for the California Department of Transportation, Sacramento.

Gilreath, A.J., Hildebrandt, W.R., 1997. Prehistoric use of the Coso volcanic field. Contributions of the University of California Archaeological Research Facility No. 56, Berkeley.

Glassow, M.A., 2002. Late Holocene prehistory of the Vandenberg region. In: Erlandson, J.M., Jones, T.L. (Eds.), Catalysts to Complexity: Late Holocene Societies of the California Coast. Cotsen Institute of Archaeology, University of California, Los Angeles, pp. 183-204.

Graumlich, L.J., 1993. A 1000-year record of temperature and precipitation in the Sierra Nevada. Quaternary Research 39, 249-255.

Grayson, D.K., 1993. The Desert's Past: a Natural Prehistory of the Great Basin. Smithsonian Institution Press, Washington, DC.
Hildebrandt, W.R., 2007. Northwest California: ancient lifeways among forested mountains, full-flowing rivers, and rocky pacific shores. In: Jones, T.L., Klar, K.A. (Eds.), California Prehistory: Colonization, Culture, and Complexity. Altamira Press, New York, pp. 83-97.

Hildebrandt, W.R., McGuire, K.R., 2002. The ascendance of hunting during the California middle archaic: an evolutionary perspective. American Antiquity 67, 231-256.

Hildebrandt, W.R., Ruby, A., 2006. Prehistoric pinyon exploitation in the Southwestern Great Basin: a view from the Coso range. Journal of California and Great Basin Anthropology 26, 11-31.

Hull, K.L., 2007. The Sierra Nevada: archaeology in the range of light. In: Jones, T.L., Klar, K.A. (Eds.), California Prehistory: Colonization, Culture, and Complexity. Altamira Press, New York, pp. 177-190.

Hull, K.L., Moratto, M.J., with contributions by McCarthy, H., Roper, C.K., Spaulding, W.G., Hale, M.R., Nilsson, E., 1999. Archeological Synthesis and Research Design, Yosemite National Park, California. USDI National Park Service Yosemite Research Center Publications in Anthropology 21, Yosemite National Park.

Jackson, T.L., Ericson, J.E., 1994. Prehistoric exchange systems in California. In: Baugh, T.G., Ericson, J.E. (Eds.), Prehistoric Exchange Systems in North America. Plenum Press, New York, pp. 385-415.

Jennings, J.D., 1964. The Desert West. In: Jennings, J.D., Norbeck, E. (Eds.), Prehistoric Man in the New World. University of Chicago Press, Chicago, pp. 149-174.

Johnson, J.R., 2000. Social responses to climate change among the Chumash Indians of South-Central California. In: McIntosh, R.J., Tainter, J.A., McIntosh, S.K. (Eds.), The Way the Wind Blows: Climate, History, and Human Action. Columbia University Press, New York, pp. 301-327.

Jones, T.L., 1992. Settlement trends along the California coast. In: Jones, T.L. (Ed.), Essays on the Prehistory of Maritime California, vol. 10. Center for Archaeological Research at Davis, University of California, Davis, pp. 1-37.

Jones, T.L., 2003. Prehistoric Human Ecology on the Big Sur Coast, Contributions of the University of California Archaeological Research Facility No. 61, Berkeley.

Jones, T.L., Ferneau, J.A., 2002a. Prehistory at San Simeon Reef: Archaeological Data Recovery at CA-SLO-179 and -267, San Luis Obispo County, California. San Luis Obispo County Archaeological Society Occasional Papers No. 16, San Luis Obispo.

Jones, T.L., Ferneau, J.A., 2002b. De-intensification along the central coast. In: Erlandson, J.M., Jones, T.L. (Eds.), Catalysts to Complexity: Late Holocene Societies of the California Coast. Cotsen Institute of Archaeology, University of California, Los Angeles, pp. 204-231.

Jones, T.L., Haney, J.W., 2005. Archaeological Evaluation of CA-MNT910, -1748/H, 1919, and -2182, Fort Hunter Liggett Military Installation, Monterey County, California. California Polytechnic State University, San Luis Obispo. Copies available from, Northwest Archaeological Information Center, Department of Anthropology, Sonoma State University, Rohnert Park, CA.

Jones, T.L., Kennett, D.J., 1999. Late Holocene climate change and cultural ecology of the Central California Coast. Quaternary Research $51,74-82$.

Jones, T.L., Klar, K.A., 2005. Diffusionism reconsidered: linguistic and archaeological evidence for prehistoric Polynesian contact with Southern California. American Antiquity 70, 457-484.

Jones, T.L., Brown, G.M., Raab, L.M., McVickar, J.L., Spaulding, W.G., Kennett, D.J., York, A., Walker, P.L., 1999. Environmental imperatives reconsidered: demographic crises in Western North America during the Medieval Climatic Anomaly. Current Anthropology 40, $137-170$.

Jones, T.L., Stevens, N.E., Jones, D.A., Fitzgerald, R.T., Hylkema, M.G., 2007. The central coast: a midlatitude milieu. In: Jones, T.L., Klar, K.A. (Eds.), California Prehistory: Colonization, Culture, and Complexity. Altamira Press, New York, pp. 125-146.

Kennett, D.J., 2005. The Island Chumash: Behavioral Ecology of a Maritime Society. University of California Press, Berkeley. 
Kennett, D.J., Bottman, T.C., 2006. Oxygen isotope analysis of California Mussel Shells (Mytilus californianus) from CA-SLO-9. In: The MiddleLate Transition on the Central California Coast: Archaeological Salvage at CA-SLO-9, Montaña de Oro State Park, San Luis Obispo County, California. Department of Social Sciences, California Polytechnic State University, San Luis Obispo. Prepared for California Department of Parks and Recreation, San Simeon.

Kennett, D.J., Conlee, C.A., 2002. Emergence of Late Holocene sociopolitical complexity on Santa Rosa and San Miguel Islands. In: Erlandson, J.M., Jones, T.L. (Eds.), Catalysts to Complexity: Late Holocene Societies of the California Coast. Cotsen Institute of Archaeology, University of California, Los Angeles, pp. 147-165.

Kennett, D.J., Kennett, J.P., 2000. Competitive and cooperative responses to climate instability in Coastal Southern California. American Antiquity 65, 379-395.

Kennett, D.J., Kennett, J.P., Erlandson, J.M., Cannariato, K.G., 2007. Human responses to middle Holocene climate change on California's Channel Islands. Quaternary Science Reviews 26, 351-367.

Klar, K.A., Jones, T.L., 2005. Linguistic evidence for a Prehistoric Polynesia-Southern California contact event. Anthropological Linguistics 47, 369-400.

Koerper, H.C., Mason, R.D., Petersen, M.L., 2002. Complexity, demography, and change in Late Holocene orange county. In: Erlandson, J.M., Jones, T.L. (Eds.), Catalysts to Complexity: Late Holocene of the California Coast. Cotsen Institute of Archaeology, University of California, Los Angeles, pp. 63-81.

LaMarche Jr., V.C., 1973. Holocene climatic variations inferred from treeline fluctuations in the White Mountains, California. Quaternary Research 3, 632-660.

LaMarche Jr., V.C., 1974. Paleoclimatic inferences from long treering records: intersite comparison shows climatic anomalies that may be linked to features of the General Circulation. Science 183, $1043-1048$

Lamb, H.H., 1965. The early medieval warm epoch and its sequel. Palaeogeography, Palaeoclimatology, Palaeoecology 1, 13-37.

Lambert, P.M., 1994. War and peace on the Western Front: a study of violent conflict and its correlates in prehistoric hunter-gatherer societies of coastal Southern California. Unpublished Ph.D. Dissertation, Department of Anthropology, University of California, Santa Barbara.

Lightfoot, K.G., Luby, E.M., 2002. Late Holocene in the San Francisco Bay area: temporal trends in the use and abandonment of shell Mounds in the East Bay. In: Erlandson, J.M., Jones, T.L. (Eds.), Catalysts to Complexity: Late Holocene Societies of the California Coast. Cotsen Institute of Archaeology, University of California, Los Angeles, pp. 263-281.

McGuire, K.R., 2007. Models made of glass: a prehistory of Northeast California. In: Jones, T.L., Klar, K.A. (Eds.), California Prehistory: Colonization, Culture, and Complexity. Altamira Press, New York, pp. $165-176$

McGuire, K.R., Hall, M.C., 1988. The archaeology of Tiefort Basin, Fort Irwin, San Bernardino, California. Report on file, San Bernardino County Archaeological Information Center, San Bernardino County Museum, Redlands.

McGuire, K.R., Hildebrandt, W.R., 1994. The possibilities of women and men: gender and the California Millingstone Horizon. Journal of California and Great Basin Anthropology 16, 41-59.

McGuire, K.R., Hildebrandt, W.R., 2005. Re-thinking great basin foragers: prestige hunting and costly signaling during the middle archaic period. American Antiquity 70, 695-712.

Mikkelsen, P.W., Hildebrandt, W.R., Jones, D.A., 2000. Prehistoric adaptations on the shores of Morro Bay Estuary: excavations at site CA-SLO-165, Morro Bay, California. San Luis Obispo County Archaeological Society Occasional Papers No. 14, San Luis Obispo.

Milliken, R.T., Fitzgerald, R.T., Hylkema, M.G., Origer, T., Groza, R., Wiberg, R., Leventhal, A., Bieling, D., Gottsfield, A., Gillette, D., Bellefemine, V., Strother, E., Cartier, R., Fredrickson, D.A., 2007. Punctuated culture change in the San Francisco Bay area. In: Jones,
T.L., Klar, K.A. (Eds.), California Prehistory: Colonization, Culture, and Complexity. Altamira Press, New York, pp. 99-123.

Moratto, M.J., 1984. California Archaeology. Academic Press, New York.

Moratto, M.J., King, T.F., Woolfenden, W.B., 1978. Archaeology and California's climate. The Journal of California Anthropology 5, $147-161$.

Munns, A.M., Arnold, J.E., 2002. Late Holocene Santa Cruz Island: patterns of continuity and change. In: Erlandson, J.M., Jones, T.L. (Eds.), Catalysts to Complexity: Late Holocene Societies of the California Coast. Cotsen Institute of Archaeology, University of California, Los Angeles, pp. 127-146.

Pilloud, M., 2005. The Medieval Climatic Anomaly and its impact on health in the Pacific Rim: a case study from Canyon Oaks, California. Unpublished Master's Thesis, Department of Anthropology, Ohio State University.

Pilloud, M., 2006. The impact of the Medieval Climatic Anomaly in prehistoric California: a case study from Canyon Oaks, CA-ALA-613/ H. Journal of California and Great Basin Anthropology 26, 179-191.

Pisias, N., 1978. Paleoceanography of the Santa Barbara basin during the last 8000 years. Quaternary Research 10, 366-384.

Preziozi, A.M., 2001. Standardization and specialization: the Island Chumash Microdrill Industry. In: Arnold, J.E. (Ed.), The Origins of a Pacific Coast Chiefdom: The Chumash of the Channel Islands. University of Utah Press, Salt Lake City, pp. 151-164.

Raab, L.M., Larson, D.O., 1997. Medieval Climatic Anomaly and punctuated cultural evolution in Coastal Southern California. American Antiquity 62, 319-336.

Raab, L.M., Yatsko, A., Garlinghouse, T.S., Porcasi, J.F., Bradford, K., 2002. Late Holocene San Clemente Island: notes on comparative social complexity in Coastal Southern California. In: Erlandson, J.M., Jones, T.L. (Eds.), Catalysts to Complexity: Late Holocene of the California Coast. Cotsen Institute of Archaeology, University of California, Los Angeles, pp. 13-26.

Rick, T., 2004. Daily activities, community dynamics, and historical ecology on California's Northern Channel Islands. Unpublished Ph.D. Dissertation, Department of Anthropology, University of Oregon, Eugene.

Rick, T.C., 2007. The Archaeology and Historical Ecology of Late Holocene San Miguel Island. Cotsen Institute of Archaeology, University of California, Los Angeles.

Rosenthal, J.S., Hildebrandt, W.R., King, J.H., 2001. Donax don't tell: reassessing Late Holocene land use in northern San Diego County. Journal of California and Great Basin Anthropology 23, 179-214.

Rosenthal, J.S., White, G.G., Sutton, M.Q., 2007. The central valley: a view from the Catbird's Seat. In: Jones, T.L., Klar, K.A. (Eds.), California Prehistory: Colonization, Culture, and Complexity. Altamira Press, New York, pp. 147-163.

Schwitalla, A., 2007. Master's Research in Progress. Department of Anthropology, California State University, Sacramento.

Stine, S., 1994. Extreme and persistent drought in California and Patagonia during Mediaeval Time. Nature 369, 546-549.

Sutton, M.Q., 1991. Archaeological investigations at Cantil, Fremont Valley, Western Mojave Desert, California. California State University, Bakersfield, Museum of Anthropology, Occasional Papers in Anthropology No. 1.

Sutton, M.Q., Basgall, M.E., Gardner, J.K., Allen, M.W., 2007. Advances in understanding Mojave Desert prehistory. In: Jones, T.L., Klar, K.A. (Eds.), California Prehistory: Colonization, Culture, and Complexity. Altamira Press, New York, pp. 229-245.

True, D.L., 1990. Site location and water supply: a perspective from northern San Diego County, California. Journal of New World Archaeology 7, 37-60.

Vellanoweth, R.L., Martz, P., Schwartz, S.J., 2002. Complexity and the Late Holocene archaeology of San Nicolas Island. In: Erlandson, J.M., Jones, T.L. (Eds.), Catalysts to complexity: Late Holocene of the California Coast. Cotsen Institute of Archaeology, University of California, Los Angeles, pp. 82-100. 
Waechter, S.A., 2005. Late period resource intensification in Sierra Valley, Eastern Plumas county: a response to the Medival Climatic Anomaly. Proceedings of the Society for California Archaeology 18, 45-52.

Warren, C.N., 1968. Cultural tradition and ecological adaptation on the Southern California Coast. In: Irwin-Williams, C. (Ed.), Archaic Prehistory in the Western United States. Contributions in Anthropology, vol. 1. Eastern New Mexico University, Paleo-Indian Institute, Portales, pp. 1-14.

Weiss, E., 2002. Drought-related changes in two hunter-gatherer California populations. Quaternary Research 58, 393-396.

Whitley, D.S., Simon, J.M., Loubser, J.H.N., 2004. Class II Inventory of the Carrizo Plain National Monument, San Luis Obispo County, California. Prepared for Bureau of Land Management, Bakersfield, California. Contract No. BAP030092. Copies available from Bureau of Land Management, 3801 Pegasus Drive, Bakersfield.
Wohlgemuth, E., 2005. The Medieval Climatic Anomaly and Central Sierra foothill prehistory. Proceedings of the Society for California Archaeology 18, 307-311.

Wormington, H.M., 1947. Prehistoric Indians of the Southwest. Denver Museum of Natural History, Denver.

Yatsko, A., 2000. Late Holocene Paleoclimatic stress and prehistoric human occupation on San Clemente Island. Unpublished Ph.D. Dissertation, Department of Anthropology, University of California, Los Angeles.

Yatsko, A., 2003. Paleodemographic change on San Clemente Island during the Medieval Climatic Anomaly. Proceedings of the Society for California Archaeology 16, 109-119.

York, A.L., 2006. An Archaeological Research Context for the Lower Santa Margarita River. EDAW Cultural Publications No. 1. EDAW Inc., San Diego. 